\title{
Evolución de la legislación brasileña sobre donación y trasplante de órganos
}

\author{
João Paulo Victorino ${ }^{\mathbf{a}}$ - Larissa Lemos Karsburg ${ }^{\mathbf{b}}$ - Emauele Seicenti de Britoc \\ - Carla Aparecida Arena Venturad
}

Resumen: El trasplante de órganos representa uno de los capítulos más exitosos en la historia de la salud mundial. Esta práctica terapéutica ya no es asociada, como otrora, al riesgo del procedimiento, sino a la oportunidad de ofrecer una nueva vida al receptor. El trasplante depende de la aceptación de la donación de órganos que, por involucrar aspectos relacionados con la vida y la muerte, implica dilemas éticos que estimulan la formulación de normas a su respecto. Este estudio tuvo como objetivo reflexionar sobre la evolución de la legislación brasileña que regula el Sistema Nacional de Trasplantes en lo que se refiere al proceso donación-trasplante, teniendo como foco los aspectos bioéticos asociados a la temática. Se identificó que la comprensión de la legislación en materia de salud propicia una actuación basada en los derechos fundamentales y la dignidad humana por parte del profesional de la salud. Desde esta perspectiva, es esencial que los profesionales de la salud posean, además de conocimientos técnicos, conocimientos jurídicos y comprensión de las normas existentes y su evolución, con el fin de garantizar los derechos fundamentales de las personas.

Palabras clave: donantes de tejidos; legislación sanitaria; legislación en ciencia y tecnología; legislación; libre elección de paciente; trasplante de órganos

a Licenciatura en Enfermería, Escuela de Enfermería de Ribeirão Preto de la Universidad de São Paulo (EERP-USP). São Paulo, Brasil.

Correo electrónico: joao.victorino@alumni.usp.br

ORCID: https://orcid.org/0000-0003-0914-9656

b Facultad de Medicina de la Fundación de la Universidad Federal de Ciencias de la Salud de Porto Alegre (UFCSPA). Rio Grande del Sur, Brasil.

Correo electrónico: larissak@ufcspa.edu.br

ORCID: https://orcid.org/0000-0002-5639-3646

c Estudiante de postgrado de la Escuela de Enfermería de Ribeirão Preto de la Universidad de São Paulo (EERP-USP).

Correo electrónico: emanuele600@usp.br

ORCID: https://orcid.org/0000-0003-1858-967X

d Posdoctorado. Profesora Titular de la Escuela de Enfermería de Ribeirão Preto de la Universidad de São Paulo (EERP-USP).

Correo electrónico: caaventu@eerp.usp.br

ORCID: https://orcid.org/0000-0003-0379-913X 
Fecha de Recepción: 06 de julio de 2018

Fecha de aceptación: 26 de novimebre de 2018
Fecha de Evaluación: 16 de octubre de 2018

Publicación en Línea: 19 de diciembre de 2018

Cómo citar: Victorino, J. P., Karsburg, L. L., Brito, E. S., \& Ventura, C. A. A. (2019). Evolución de la legislación brasileña sobre donación y trasplante de órganos. Revista Latinoamericana de Bioética, 19(36-1). https://doi.org/10.18359/rlbi.3551

\title{
Evolution of the Brazilian legislation on organ donation and transplantation
}

\begin{abstract}
Organ transplantation represents one of the most successful chapters in the history of world health. This therapeutic practice is no longer associated, as once, with the risk of the procedure, but with the opportunity to offer a new life to the recipient. The transplant depends on the acceptance of the donation of organs that, by involving aspects related to life and death, implies ethical dilemmas that stimulate the formulation of norms in this regard. This study aimed to reflect on the evolution of Brazilian legislation that regulates the National Transplant System in regard to the donation-transplant process, focusing on the bioethical aspects associated with the subject. It was identified that the understanding of health legislation encourages action based on fundamental rights and human dignity by the health professional. From this perspective, it is essential that health professionals possess, in addition to technical knowledge, legal knowledge and understanding of existing norms and their evolution, in order to guarantee the fundamental rights of people.
\end{abstract}

Keywords: tissue donors; health legislation; science and technology legislation; legislation; free patient choice; organ transplant

\section{Evolução da legislação brasileira sobre doação e transplante de órgãos}

Resumo: O transplante de órgãos representa um dos capítulos de mais sucesso na história da saúde mundial. Essa prática terapêutica já não é associada, como antes, ao risco do procedimento, mas, sim, à oportunidade de oferecer uma nova vida ao receptor. O transplante depende da aceitação da doação de órgãos que, por envolver aspectos relacionados com a vida e a morte, implica dilemas éticos que estimulam a formulação de normas a seu respeito. Este estudo teve como objetivo refletir sobre a evolução da legislação brasileira que regula o Sistema Nacional de Transplante no que se refere ao processo doação-transplante, tendo como foco os aspectos bioéticos associados à temática. Identificou-se que o entendimento da legislação em matéria de saúde propicia uma atuação baseada nos direitos fundamentais e na dignidade humana por parte do profissional da saúde. A partir dessa perspectiva, é essencial que os profissionais da saúde possuam, além de conhecimentos técnicos, conhecimentos jurídicos e entendimento das normas existentes e sua evolução, com o fim de garantir os direitos fundamentais das pessoas.

Palavras-chave: doadores de tecidos; legislação sanitária; legislação em ciência e tecnologia; legislação; livre escolha do paciente; transplante de órgãos. 


\section{Introducción}

El trasplante de órganos es el tratamiento que consiste en la sustitución de un órgano dañado por otro sano, de un donante vivo o fallecido. Beneficia a miles de personas, siguiendo criterios clínicos y legales establecidos en el país (Hospital Israelita Albert Einstein, 2019).

Debido a la importancia de la adopción de normas que tornen seguro y transparente el proceso de donación y trasplante de órganos, algunos temas básicos deben ser cubiertos por la legislación, como el permiso para realizar el trasplante con donante fallecido y con donante vivo, los criterios para el diagnóstico de muerte encefálica, la forma de consentimiento para la donación de órganos, la forma de acreditación de hospitales y profesionales, el registro y la confidencialidad de los datos de donantes y receptores, los criterios para la asignación de órganos y la inclusión en la lista de espera, la prohibición del comercio de órganos, la restricción del trasplante de donante vivo sin parentesco y las sanciones a las infracciones. El enfoque de esas cuestiones es orientado por lineamientos de la Organización Mundial de la Salud (2010 y 2016) y de sociedades científicas como la Sociedad Internacional de Trasplante.

Cabe destacar que los gobiernos adoptan diferentes modelos legales e institucionales que consideran más adecuados con el propósito de reducir y tratar de eliminar las listas de esperas (Chaparro, 2017). La normativa sobre donación de partes del cuerpo humano puede clasificarse según la forma que adopte el consentimiento de la donación. Un primer modelo se basa en la voluntad expresa del donante, por lo que se denomina consentimiento informado. Un segundo modelo asume que todas las personas son potenciales donantes, a menos que manifiesten su negativa a la donación; este modelo se denomina de presunción de donación. En ambos casos, se presentan dos variantes básicas: si se permite o no que la familia se oponga a la donación (Chaparro, 2017).

La donación de órganos y tejidos humanos para trasplante está directamente relacionada a los valores morales, éticos y religiosos de las personas, pues estimula a los individuos a pensar en la noción de finitud y en su relación con el cuerpo después de la muerte (Roza, 2010).

Aunque la donación represente una conducta social moralmente buena, podemos intuir que aún no ha sido incorporada a la moral común, por diversos aspectos. Entre ellos destacamos el descrédito en el funcionamiento y estructura del sistema de salud, en la asignación de recursos, en la relación de confianza entre profesional de salud y paciente, acceso equitativo y justo; en la confidencialidad donante/receptor; consentimiento libre y esclarecido, respeto a la autonomía; la defensa de la vida y el carácter innovador y reciente de esta posibilidad terapéutica, aún en construcción (Acero, 2011).

Así, esta es una discusión ética, que forma la base para una conducta correcta y justa apoyada en la responsabilidad de sus actos, como no matar. Sin embargo, la simple aplicación de los diferentes principios de autonomía, beneficencia, no maleficencia y justicia, en determinar cuándo un principio justifica prioridad sobre el otro, no colabora en el esclarecimiento de cuestiones morales, tales como la distribución equitativa de órganos frente a la poca disposición de los donantes (en el caso de los donantes vivos) (Sharif, 2018; Roza, 2010; Kennedy et al, 1998; De Ortúzar, Soratti \& Vélez, 1997). En el caso de los donantes vivos, se destaca la resolución de muerte y la protección de la autonomía de los donantes ante el consentimiento informado (en participar en los casos de donantes vivos) (Roza, 2010; De Ortúzar, Soratti \& Vélez, 1997).

En vista de esto, este estudio tuvo como objetivo reflexionar sobre la evolución de la legislación brasileña sobre donación y trasplante de órganos en el período 1968-2017.

\section{Evolución de la legislación sobre donación de órganos en Brasil}

\section{Ley . $^{\circ} 5.479 / 68$}

La Ley n. ${ }^{\circ}$ 5.479/68 disponía sobre la ablación e implante de tejidos, órganos y partes del cuerpo humano con fines terapéuticos y científicos en Brasil. Esa misma ley establecía, en su artículo $1^{\circ}$, la disposición gratuita de una o más partes del cuerpo post mortem. En tal sentido, el artículo $3^{\circ}$ de esa ley establecía 
que la extracción de órganos solo podía llevarse a cabo después de la manifestación expresa de la voluntad del disponente o por manifestación de la voluntad por medio de un instrumento público, en los casos de disponentes incapaces y/o analfabetos. Se establecía también, por este mismo artículo, la autorización para la extracción de órganos a través del consentimiento por escrito del cónyuge, de los descendientes, ascendientes y colaterales, o incluso de las entidades civiles y religiosas responsables por el destino de los despojos (Brasil, 1968).

Esta ley también garantizaba a todas las personas capaces el derecho a disponer de partes u órganos del propio cuerpo vivo, en caso de órganos dobles, tejidos, vísceras o partes, desde que no implicara lesiones o mutilación grave para el donante y atendiera a una necesidad terapéutica probadamente indispensable para quien recibiría el trasplante.

\section{Ley $n .^{\circ} 8.489 / 92$}

En 1988, se promulgó la Constitución Brasileña que instituyó en su párrafo 199, \$4 que

la ley dispondrá sobre las condiciones y los requisitos que faciliten la remoción de órganos, tejidos y sustancias humanas para fines de trasplante, investigación y tratamiento, así como como la recolección, procesamiento y transfusión de sangre y sus derivados, siendo vedado cualquier tipo de comercialización. (Brasil, 1988)

A partir de ahí la retirada de órganos y tejidos de donantes fallecidos, y también entre vivos con fines científicos, humanitarios y terapéuticos, pasó a regirse por la Ley $n^{\circ} 8.489$, promulgada el 18 de noviembre de 1992 (Brasil, 1992), acerca de la ablación y el trasplante de tejidos, órganos y partes del cuerpo humano con fines terapéuticos y científicos, entre otras disposiciones, alterando lo dispuesto por el artículo $3^{\circ}$ de la Ley n. ${ }^{\circ}$ 5.479/68 (Brasil, 1968):

Art. $3^{\circ} \mathrm{El}$ permiso para utilización, para las finalidades determinadas en el artículo $1^{\circ}$ de esta ley, deberá condicionarse al cumplimiento de lo siguiente:

I - Ser el deseo expreso del dador, manifestado en vida a través de documento personal u oficial;

II - En la ausencia del documento mencionado en el inciso I de este artículo, la extracción de órganos procederá de no haber declaración en contrario del cónyuge, ascendiente o descendiente.
A partir de ese momento comenzó a registrarse en documentos personales $u$ oficiales el deseo de convertirse en donante de órganos en caso de fallecimiento. Por otra parte, en el segundo inciso de dicho artículo se establecía la decisión del cónyuge, ascendente o descendente, cuando la muerte era notificada y no existiera manifestación en contrario en algún tipo de registro.

En ese momento surgen los impasses éticos relacionados al respeto con la autonomía del sujeto. Se trata, pues, de un principio bioético por el cual se entiende que el personal responsable tiene el derecho y también el deber de actuar según su propia voluntad. En esta perspectiva, se hace necesario que el sujeto sea capaz de deliberar sobre sus propias voluntades/elecciones, para que entonces ocurra la toma de decisión (Dantas, 2012).

En los últimos años, la tasa de analfabetismo de las personas con edad igual o superior a 15 años fue estimada en el 7\% de los encuestados, según el informe del Instituto Brasileño de Geografía y Estadística (IBGE) por medio de la Encuesta Nacional por Muestra de Domicilios (PNAD) referente al año 2017, (11,5 millones de analfabetos). En este mismo período, la tasa de analfabetismo entre individuos con edad mayor o igual a 60 años fue del 19,3\% (IBGE, 2017).

$\mathrm{El}$ analfabetismo sumado al contingente de personas semialfabetizadas en Brasil compromete la autonomía de los brasileños, considerando que la ausencia de informaciones necesarias e indispensables limita la decisión libre de las personas sobre sus destinos.

En el marco del proceso donación-transplante de órganos, la falta de información, o la incapacidad de comprender de manera adecuada las informaciones prestadas por parte del equipo multiprofesional que integra los servicios de salud especializados en la temática, sumados al bajo nivel de escolaridad de los familiares, puede generar interpretaciones ambiguas acerca de cómo se devolverá el cuerpo después de la retirada de los órganos y/o tejidos y, sobre todo, en lo que se refiere a la distribución equitativa de estos órganos y/o tejidos (Roza, 2010), pudiendo generar resultados contraproducentes en un escenario en el cual la negativa familiar se caracteriza como la mayor causa de impedimento para la donación de órganos (АВTO, 2019). 
En el principialismo de la bioética, naturalmente, cuestiones, como la falta de información, no garantizan una decisión autónoma y, mucho menos, justa, por la vulnerabilidad de los involucrados. Sólo podemos hablar en ejercicio pleno de autonomía, cuando hay intercambio de conocimiento e información del equipo de salud para el paciente, ofreciendo datos importantes, en lenguaje accesible, para que cualquier decisión pueda ser tomada, garantizando la competencia de todos los miembros involucrados en la situación. (Roza, 2010, p. 420. Traducción nuestra)

Se trata, pues, de un principio de la teoría principialista de la bioética que retrata el poder de autodeterminación del hombre (Ribeiro, 2006).

De acuerdo con la Ley en cuestión, el artículo 10, que trataba de la disposición gratuita de órganos, tejidos o partes del propio cuerpo vivo para fines humanitarios y terapéuticos, modifica los párrafos de la ley anterior $y$, en su párrafo $1^{\circ}$, establece que el trasplante de donantes vivos quedará limitado a la donación entre abuelos, nietos, padres, hijos, tíos, sobrinos, primos hasta el segundo grado inclusive, cuñados y cónyuges. En los casos en que la relación entre las personas no corresponda con alguno de los tipos detallados en el párrafo $1^{\circ}$, la donación solo se llevará a cabo mediante autorización judicial (Brasil, 1992).

Además, de acuerdo con el párrafo $3^{\circ}$, cabe al disponente autorizar y especificar el órgano, tejido o parte del cuerpo a ser retirado para el trasplante.

\section{Decreto n. ${ }^{\circ} 879 / 93$}

El Decreto n. ${ }^{\circ} 879$, de 22 de julio de 1993, reglamenta la Ley n. ${ }^{\circ} 8.489$, de 18 de noviembre de 1992, que trata de la ablación e implante de tejidos, órganos y partes del cuerpo humano con fines terapéuticos, científicos y humanitarios (Brasil 1993; Brasil, 1992).

Establece en el artículo $2^{\circ}$ la prohibición de comercializar tejidos, órganos y partes del cuerpo humano. También establece destacadamente, en su artículo $5^{\circ}$ que trata sobre el autotransplante, el consentimiento del propio individuo, o de su representante legal si aquel fuera civilmente incapaz. Para la extracción de órganos o partes del cuerpo se estipula, en el artículo $8^{\circ}$ de dicha ley, la obligación de llevar a cabo exámenes diagnósticos y la confirmación de la muerte encefálica. Sin embargo, el diagnóstico, así como la comprobación de la muerte, no deben relacionarse con la posibilidad de la utilización de los órganos, tejidos o partes del cuerpo humano para trasplante.

El instrumento legal también establece que los exámenes diagnósticos para confirmación de la muerte encefálica, que deben cumplir los criterios de la Resolución CFM n. ${ }^{\circ}$ 1480/97, de 8 de agosto de 1997, solo pueden ser realizados por médicos que no realicen y/o no integren los equipos de trasplante (CFM, 1997). La familia también tiene el derecho de elegir un médico de confianza en el acto de verificación y certificación de la muerte encefálica (Brasil, 1993).

El artículo 12 permite que personas mayores de edad y capaces dispongan, de forma gratuita, de tejidos, órganos o partes del propio cuerpo vivo. Establece que este tipo de procedimiento solo sea permitido en casos de órganos dobles, partes de órganos, tejidos, vísceras o partes del cuerpo que no impidan al organismo del donante continuar viviendo sin riesgo para su integridad y sin grave compromiso de sus funciones vitales o salud mental. Impone como condición, además, que el procedimiento no cause daño o deformación inaceptable y que sea motivado por una necesidad terapéutica probadamente indispensable para la persona receptora, conforme dispone el párrafo $3^{\circ}$ de este artículo (Brasil, 1993).

Para que se realice la donación denominada donación inter vivos, el donante debe estar en buen estado de salud y debe existir probada compatibilidad sanguínea e inmunológica entre él y el receptor, conforme lo dispuesto por los párrafos $1^{\circ}$ y $2^{\circ}$ de este artículo:

\footnotetext{
$\S$. 1. El donante será previa y obligatoriamente informado acerca de las consecuencias y los posibles riesgos de la ablación de tejidos, órganos o partes de su cuerpo. La información debe ser verbal y por escrito, debiendo el donante manifestar explícitamente su consentimiento.

§. 2. La información verbal y escrita brindada al donante cubrirá todas las circunstancias relacionadas con la ablación de tejidos, órganos o partes del cuerpo, y los riesgos, tanto físicos como psicológicos, involucrados en la intervención.
} 
Además, para que la donación inter vivos pueda ser llevada a cabo, el artículo 14 de este decreto impone la obligación de que el donante firme un documento especificando los tejidos, órganos o partes del cuerpo que dona, y afirmando ser consciente, a raíz de las informaciones que le fueron brindadas según se determina en los párrafos $1^{\circ} \mathrm{y}$ $2^{\circ}$ del artículo 13, de todos los hechos y riesgos de la intervención, o derivados de ella (Brasil, 1993).

A pesar de tener el derecho de disponer de sus órganos, dentro del marco normativo vigente, el artículo 15 de ese decreto garantiza al donante la revocación del consentimiento prestado (Brasil, 1993).

Se impone también, en las donaciones inter vivos, el anonimato del acto a todo el equipo que integra el Servicio de Trasplantes de Órganos y Tejidos - Hospital y Centro de Notificaciones (Brasil, 1993).

La donación inter vivos también puede ser autorizada judicialmente, cuando el destinatario no estuviera incluido en los casos especificados en el párrafo $1^{\circ}$ del artículo. 12. En estos casos, es obligatoria dicha autorización judicial, que debe ser precedida por la constatación de la salud mental del donante, la inexistencia de cualquier tipo de retribución, ya sea pecuniaria, material u otra, la inexistencia de coacción, el respeto al anonimato del donante, del receptor y del término de la donación, según lo establecido en el artículo 18 y sus incisos (Brasil, 1993).

Es obligatoria la notificación una vez comprobada la muerte encefálica. Debe ser cursada por la dirección del hospital en el cual la muerte encefálica fue diagnosticada, con urgencia e inmediatamente después de su constatación, al Centro de Notificación de la Secretaría de Estado de la Salud, de acuerdo con el artículo 19 y los párrafos $1^{\circ} \mathrm{y}$ $2^{\circ}$, que tratan sobre la notificación obligatoria para hospitales públicos y privados (Brasil, 1993).

Se incluyen también como motivos de notificación al Centro de Notificación de la Secretaría, según los incisos I, II y III del artículo 20, párrafos $1^{\circ}$ y $2^{\circ}$ (Brasil, 1993):

I - La existencia de paciente-receptor con enfermedad que requiera trasplante;

II - El fallecimiento de individuo que cumpla con los requisitos establecidos en el artículo $7^{\circ}$;
III - La donación en vida de tejidos, órganos o partes del cuerpo.

El párrafo $1^{\circ}$ trata de la información del paciente enfermo a ser suministrada por la dirección del hospital en el momento de la notificación, inmediatamente después de la indicación del trasplante, con el fin de integrar la Base de Datos Técnica del Centro de Notificación (Brasil, 1993).

Luego de los criterios para la realización de exámenes clínicos y para la comprobación de la muerte encefálica, y de determinar la obligatoriedad de la notificación al Centro, se establecen, en el artículo 22, los criterios de selección de los potenciales destinatarios, tales como criterios de registro técnico (orden cronológico de inscripción, cuando sea necesaria la comprobación de la compatibilidad sanguínea e inmunológica y la gravedad de la enfermedad). En todos los casos, el Centro de Notificación de la Secretaría de Salud del Estado seleccionará más de un individuo, hasta un máximo de diez, y los enviará al hospital responsable por realizar el trasplante (Brasil, 1993).

Estos criterios se basan, entre muchos aspectos, en el principio de igualdad de todos los sujetos ante la ley y el derecho social a la salud, así como al principio de equidad en salud, por medio del cual se establecen los criterios de priorización de los pacientes en la cola para un trasplante.

Por el principio de igualdad, todos los individuos deben recibir un trato igual. Implícita en esta noción está la idea de que los individuos son todos iguales, tienen los mismos derechos y, por lo tanto, merecen los mismos recursos. Se trata de un principio basado en una moralidad de derechos, diferente, sin embargo, de las moralidades fundadas en derechos de trabajo o de propiedad, que juzgan justa la distribución de los recursos de acuerdo con la contribución de los individuos para su obtención. La igualdad es, pues, basada en derechos adquiridos por la participación en la colectividad, los derechos de ciudadanía. El principio de equidad reconoce que los individuos son diferentes entre sí y, por lo tanto, merecen tratamiento diferenciado que elimine (o reduzca) la desigualdad (Medeiros, 1999). En este caso, los individuos más graves tienden a ser considerados como prioridades para la asignación de órganos o tejidos para trasplante, a depender del 
conjunto de criterios clínicos y jurídicos establecidos por el aparato legal vigente en el país.

En lo que se refiere a la noción de derecho, se asume que este es inherente a la acción humana, orientándola desde el acto de respirar hasta el de realizar negocios jurídicos de grandes repercusiones. Por esa razón se dice que el derecho es producto de una construcción social, por lo tanto, resultado de la realidad humana, cultural e histórica (Freitas, 2007). Se parte, pues, de la noción holística que atribuye diferentes significados a la existencia humana, de ahí su carácter dinámico, porque la propia sociedad va discutiéndolo y resignificándolo de vez en cuando, buscando adecuarse a los constantes cambios y necesidades sociales (Ventura et al., 2012).

\section{Ley n. ${ }^{\circ}$ 9.434/97}

La Ley n. ${ }^{\circ}$ 9434, también conocida como Ley de los Trasplantes (Brasil, 1997), se ocupa de la disposición post mortem de tejidos, órganos y partes del cuerpo humano para trasplante; de los criterios para el trasplante con donante vivo y de las sanciones penales y administrativas en caso de incumplimiento. Fue reglamentada inicialmente por el Decreto n. ${ }^{\circ} 2.268 / 97$, que también estableció el Sistema Nacional de Trasplantes (SNT), los órganos de los Estados y los Centros de Notificación, Captación y Distribución de Órganos (CNDCO) y, actualmente, está reglamentada por el Decreto n. ${ }^{\circ}$ 9.175/17, que reorganiza el SNT a nivel de los estados con la obligación de crear centros estatales de trasplante en cada estado del país que realice procedimientos de trasplante.

A continuación se detallan los diferentes capítulos que se relacionan con esta ley.

\section{Capítulo I. Disposiciones generales}

La realización de trasplantes o injertos de tejido, órganos o partes del cuerpo humano solo podrá ser autorizada después de la realización de todos los exámenes de infección y contagio, en el donante, exigidos para la sangre para donación, según lo dispuesto en la Ley n. ${ }^{\circ} 7.649$, de 25 de enero de 1988, y las reglamentaciones del Poder Ejecutivo.
Capítulo II. Disposición post mortem de tejidos, órganos y partes del cuerpo humano para trasplante

El artículo $3^{\circ}$ de este capítulo establece que la extracción post mortem de tejidos, órganos o partes del cuerpo humano destinadas al trasplante o tratamiento es precedida por un diagnóstico de muerte encefálica realizado siguiendo criterios clínicos y técnicos establecidos por la resolución del Consejo Federal de Medicina. Garantiza, además, a la familia del donante fallecido, la indicación de un médico de confianza para supervisar el proceso de determinación de la muerte encefálica. Otra disposición que se imparte en este capítulo es que, después de la extracción de órganos del donante fallecido, el cuerpo debe ser recompuesto y entregado a sus familiares o responsables legales (Brasil, 1997).

La donación supuesta es instituida en el artículo $4^{\circ}$ de este capítulo; esto es, se supone que el individuo es un donante de órganos, excepto en caso de manifestación de voluntad contraria, expresada mediante la inserción de la leyenda "no donante" en un documento de identidad (1993).

\section{Capítulo III. Disposición de tejidos, órganos y partes del cuerpo humano vivo para fines de trasplante o tratamiento}

El artículo $9^{\circ}$ este capítulo trata de la disposición de tejidos, órganos o partes del propio cuerpo vivo para trasplante. Sus párrafos establecen el principio de la no maleficencia, previendo maneras de que sean evitadas, o de que no sean practicadas, acciones capaces de causar daños a los individuos, tales como las relacionadas con el autotrasplante, el rechazo en el momento de la donación -por parte del donante, tejido o parte del cuerpo humano, además de las personas legalmente incapaces y mujeres embarazadas (Brasil, 1997).

\section{Capítulo V. Sanciones penales y administrativas. Sección I - Delitos}

El artículo 14 caracteriza como delito la extracción de tejidos, órganos o partes del cuerpo de una persona o de un cadáver, realizada en desacuerdo con las disposiciones de esta ley, estableciendo 
pena de prisión de dos a seis años y multa de 100 a 360 días-multa (Brasil, 1997).

De acuerdo con el párrafo $1^{\circ}$, se considera delito la donación de órganos, tejidos o partes del cuerpo humano a cambio de un pago o promesa de recompensa, o por otro motivo vil, estableciendo pena de prisión de tres a ocho años y multa de 100 a 150 días-multa (Brasil, 1997).

La legislación también prevé los casos en que el delito involucra a una persona viva, con consecuencias, para la víctima, de:

I - Incapacidad para realizar las actividades habituales durante más de treinta días;

II - Peligro de vida;

III - Debilidad permanente de un miembro, sentido o función;

IV - Aceleración del parto, siendo la pena de prisión de tres a diez años y multa de 100 a 200 días-multa, (Brasil, 1997)

En los casos en que el delito involucre a una persona viva, para la cual las consecuencias sean:

I - Incapacidad para trabajar;

II - Enfermedad incurable;

III - Pérdida o disfunción de un miembro, sentido o función;

IV - Deformidad permanente;

$\mathrm{V}$ - Aborto, la pena será de prisión de cuatro a doce años y multa de 150 a 300 días-multa, (Brasil, 1997)

Si el delito involucra a una persona viva y causa su muerte, la pena será de prisión de ocho a veinte años y multa de 200 a 360 días-multa.

También se caracteriza como delito la compra o venta de tejidos, órganos o partes del cuerpo, estableciéndose pena de prisión de tres a ocho años y multa de 200 a 360 días-multa.

El párrafo único de este artículo establece que la pena será la misma para aquel que promueve, intermedia, facilita o recibe cualquier tipo de beneficio con la transacción. Así mismo, se caracteriza como delito, de acuerdo con el artículo 16, realizar trasplante o injerto usando órganos, tejidos o partes del cuerpo humano teniendo conocimiento de que el material fue obtenido en forma ilegal. En estos casos, la pena es de prisión de uno a seis años y multa de 150 a 300 días-multa (Brasil, 1997).
También es considerado delito, según el artículo 18 , la realización de trasplante o injerto en desacuerdo con las disposiciones del párrafo único del artículo 10 de esta ley, con pena de prisión de seis meses a dos años. La pena es la misma cuando se violan las disposiciones del artículo 19, que establece la obligación de recomponer el cadáver después de la extracción de órganos, tejidos o partes del cuerpo, devolviéndole un aspecto digno para su sepultura, así como dejar de entregar o retrasar su entrega a los familiares o interesados (Brasil, 1997).

Tiene también carácter delictivo, y está sujeto a pena, el acto de publicar anuncio y atraer al público para la donación de órganos en violación de las disposiciones del artículo 11, con pena de multa de 100 a 200 días-multa.

En los casos de los delitos previstos en los artículos 14, 15, 16 y 17, la unidad de salud, así como los equipos médicos y quirúrgicos que participan del proceso de donación y trasplante, pueden ser temporal o permanente inhabilitados por las autoridades competentes.

De acuerdo con el párrafo $1^{\circ}$ del artículo 21 , cuando la institución es privada, la autoridad responsable por la evaluación del caso y por la imposición de sanciones puede imponerle una multa de 200 a 360 días-multa y, en casos de reincidencia, puede suspender sus actividades temporal o definitivamente sin derecho a ningún tipo de indemnización o compensación por las inversiones ya realizadas. Además, el párrafo $2^{\circ}$ de dicho artículo prevé que cuando la institución es privada quedará prohibida de establecer relaciones contractuales o convenios con entidades públicas, e impedida, durante cinco años, de beneficiarse de créditos obtenidos con instituciones gubernamentales o con instituciones cuyo accionista sea el propio Estado (Brasil, 1997).

\section{Decreto 2.170/97}

Promulgada el 4 de marzo de 1997, aproximadamente un mes después de la Ley 9.434, este decreto impuso la obligatoriedad de la manifestación de elección; o sea, el documento de identidad debe necesariamente contener la expresión "donante de órganos o tejidos" o la expresión "no donante" (Brasil, 1997). 


\section{Decreto 2.268/97}

Este decreto reglamentaba la Ley 9.434/97, que trataba sobre la extracción de órganos, tejidos y partes del cuerpo humano para trasplante y tratamiento, entre otras disposiciones. En su artículo $1^{\circ}$ preveía que la extracción y donación de tejidos, órganos y partes del cuerpo humano y su utilización en trasplantes, injertos u otros fines terapéuticos de acuerdo con la Ley n. ${ }^{\circ}$ 9.434, de 4 de febrero de 1997, debía observar las disposiciones de este decreto. Por lo tanto, sangre, esperma y óvulos no están incluidos entre los tejidos alcanzados por este decreto (Brasil, 1997).

Establecía también la organización de todo el Sistema Nacional de Trasplantes (SNT), designándolo responsable por desarrollar el proceso de captación y distribución de tejidos, órganos y partes del cuerpo humano con fines terapéuticos en el país.

En ese mismo decreto, el artículo $3^{\circ}$ establece todos los organismos que integran el SNT, como el Ministerio de la Salud; las Secretarías de Salud de los Estados y del Distrito Federal u organismos equivalentes; las Secretarías de Salud de los municipios u organismos equivalentes; los hospitales autorizados y, finalmente, la red de servicios auxiliares necesarios para la realización de trasplantes (Brasil, 1997).

El contenido principal de este decreto se refiere al carácter de la donación. En el párrafo $1^{\circ}$ del artículo 14 se estableció que la manifestación negativa sobre la extracción de órganos, tejidos o partes sería reconocida si constase con la expresión "no donante de órganos y tejidos” en un documento oficial, tal como la cédula de identidad, emitida por los organismos de identificación del Gobierno Federal, de los estados y del Distrito Federal, o en la licencia de conducir ( $\mathrm{CNH}$ - Carteira Nacional de Habilitação). Los mismos organismos públicos mencionados en este párrafo deberían incluir, en los formularios a ser completados para la solicitud de los documentos mencionados, espacio para ser utilizado por aquellos que deseaban expresar su voluntad con respecto a la donación de órganos, tejidos o partes del cuerpo después del diagnóstico de muerte encefálica, de acuerdo con lo dispuesto en el párrafo $4^{\circ}$ de esta ley (Brasil, 1997).
El párrafo $5^{\circ}$ del artículo 14 estableció la prohibición, para los funcionarios de los organismos de expedición de los documentos mencionados, y bajo pena administrativa, de inducir la opción del interesado, excepción hecha sobre la obligación de avisar al mismo que la ausencia de manifestación lo tornaría supuesto donante de sus órganos ante el fallecimiento (Brasil, 1997).

Aun habiendo optado por ser donante o no donante, el individuo podía comparecer en cualquier momento a los organismos oficiales de identificación civil y de tránsito que llevaron a cabo el registro de su opción en la forma dispuesta por el párrafo $1^{\circ}$ de este artículo, y renovar los documentos.

\section{Resolución n.` 1.480/97 del Consejo Federal de Medicina}

El artículo $3^{\circ}$ de la Ley 9.434/97 atribuyó a la elección de los criterios para la definición de muerte encefálica al Consejo Federal de Medicina (CFM), el cual promulgó esa resolución el 8 de agosto de 1997 (CFM, 1997).

En el artículo $1^{\circ}$ se estableció que la caracterización de la muerte encefálica requiere pruebas clínicas y de laboratorio estandarizadas, que deben ser registradas en el formulario de «Declaración de Muerte Encefálica». Los criterios clínicos son: coma arreactivo con ausencia de actividad motora supraespinal y apnea; los exámenes auxiliares, por su parte, deben mostrar ausencia de actividad electroencefálica, ausencia de actividad metabólica o ausencia de perfusión sanguínea cerebral (CFM, 1997).

La «Declaración de Muerte Encefálica» consta de dos exámenes clínicos, realizados por médicos diferentes, y un examen auxiliar. En el artículo $5^{\circ}$ se establece el intervalo mínimo que debe observarse entre los exámenes clínicos: de 7 días a 2 meses incompletos: 48 horas; de 2 meses a 1 año incompleto: 24 horas; de 1 año a 2 años incompletos: 12 horas; $y$ a partir de 2 años: 6 horas. El examen clínico, a su vez, comprende la observación de coma arreactivo, pupila fija y arreactiva bilateralmente, ausencia de reflejo corneopalpebral bilateral, ausencia de reflejo vestíbulo-ocular bilateral, ausencia de respuesta a prueba calórica bilateral, ausencia de reflejo de tos y apnea (CFM, 1997). 
El artículo $9^{\circ}$ de la citada resolución establece que después de la confirmación de la muerte encefálica el director clínico del hospital, o persona por él indicada, debe notificar a los responsables legales por el paciente sobre el diagnóstico, así como informar al Centro de Notificación, Captación y Distribución de Órganos vinculado al hospital. Las principales diferencias entre la Resolución n. $.^{\circ} 1.480 / 97$ y n. ${ }^{\circ} 2.173 / 17$ pueden verse en la tabla 1 .

Tabla 1. Criterios clínicos para el diagnóstico de muerte encefálica (ME) en adultos en Brasil

Resolución CFM n. ${ }^{\circ}$ 1.480/97

\section{Resolución CFM n. ${ }^{\circ}$ 2.173/17}

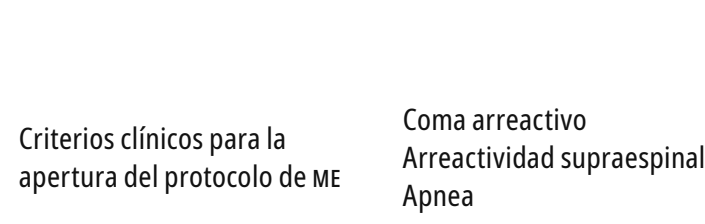

Criterios clínicos para la Arreactividad supraespinal Apnea

Coma arreactivo

Arreactividad supraespinal

Apnea

Lesión encefálica de causa conocida e

irreversible

Temperatura corporal $>35^{\circ} \mathrm{C}$

Sat. $\mathrm{O}_{2}>94 \%$

PAS $\geq 100 \mathrm{mmHg}$ para adultos

$\begin{array}{lll}\begin{array}{l}\text { Tiempo de observación para la } \\ \text { apertura del protocolo }\end{array} & \text { No había } & \text { Mínimo de } 6 \text { horas } \\ & & \text { En casos de encefalopatía hipóxico-isquémica: } \\ & 24 \text { horas. }\end{array}$

Intervalo mínimo entre los Más de 2 años: 6 horas Más de 2 años: 1 hora
exámenes clínicos

Dos exámenes clínicos realizados por diferentes
médicos

Confirmación de la ME

Exámenes auxiliares realizados a intervalos de tiempos variables. Los exámenes auxiliares deben demostrar:

- ausencia de actividad electroencefálica, ausencia de actividad metabólica cerebral 0 ausencia de perfusión sanguínea cerebral.

El Decreto 2.268/97 (derogado por el Decreto 9.175/17) establecía que uno de los dos médicos Capacitación de los médicos intervinientes
Dos exámenes clínicos realizados por diferentes médicos, específicamente capacitados para confirmar el coma arreactivo y la ausencia de función troncoencefálica;

1 prueba de apnea;

1 examen auxiliar que compruebe la ausencia de actividad cerebral. Este examen debe comprobar:

- ausencia de perfusión sanguínea encefálica 0 actividad metabólica encefálica 0 ausencia de actividad electroencefálica.

Se considerará específicamente capacitado el médico que cuente con un año de experiencia en la atención de pacientes en estado de coma y que haya asistido o realizado al menos diez determinaciones de $\mathrm{ME}$, o que haya realizado curso de capacitación para la determinación de la ME.

Uno de los médicos debe ser especialista en una de las siguientes especialidades: medicina intensiva, medicina intensiva pediátrica, neurocirugía o medicina de emergencia.

Ninguno de estos médicos podrá formar parte del equipo de trasplante.

Fuente: Adaptado de Conselho Federal de Medicina (2017). Resolução cfm n. 2.173/17. Brasília: CFM, 2017. 
Medidas provisorias $1.718 / 98$, 1.718/99, 1.896/99, 1.959/99, $1.959 / 00,2.083 / 00$ y $2.083 / 01$

Las medidas provisorias añadieron un párrafo al artículo $4^{\circ}$ de la Ley 9.434/97. Así, en el artículo $1^{\circ}$ se establece que el artículo $4^{\circ}$ de la Ley n. ${ }^{\circ} 9.434$, de 4 de febrero de 1997, pasa a regir con el agregado del siguiente párrafo: " $\$ 6^{\circ}$ En ausencia de la manifestación de voluntad del potencial donante, el padre, madre, hijo o cónyuge podrá manifestarse en contra de la donación, lo que será obligatoriamente acatado por los equipos de trasplante y de ablación".

Además, a partir de la MPV n. ${ }^{\circ}$ 1.959-27, del 2000, se altera lo dispuesto por la Ley n. $.^{\circ} 9.434 / 97$. El principal cambio está relacionado con la figura del donante supuesto, que deja de existir (Brasil, 2000).

Por lo tanto, todas las manifestaciones de voluntad sobre la extracción post mortem de órganos, tejido o partes del cuerpo pierden valor legal, pasando la donación a ser realizada mediante autorización de familiares en línea directa o colateral hasta el segundo grado, o de cónyuge, firmada en documento subscripto por dos testigos presentes durante la verificación de la muerte.

\section{Ley $n .^{\circ} 10.211 / 2001$}

Con la promulgación de la Ley 10.211 se ratifica que todas las formas de registro en documentos oficiales pierden valor; la donación deja de ser supuesta y pasa a ser denominada consentida (Brasil, 2001).

Transformar el acto de donación en algo compulsorio contrariaba no solo la Constitución (respeto al principio de la dignidad de la persona humana), sino también los principios bioéticos, y la propia noción civilista de autonomía, de capacidad para consentir.

\section{Ley $n .^{\circ} 11.521 / 2007$}

La Ley de Donación y Trasplante de Órganos, Tejidos o partes del cuerpo humano altera la Ley n..$^{\circ}$.434, de 1997, para permitir la retirada, por el Sistema Único de Salud, de órganos y tejidos de donadores que se encuentren en hospitales no autorizados a realizar trasplantes (Brasil, 2007).
En tales casos, el párrafo único de esta ley establece que, después de la notificación, las instituciones no autorizadas a llevar a cabo procedimientos de ablación y trasplante deben autorizar la remoción inmediata del paciente o permitir el acceso a sus instalaciones a los equipos médico-quirúrgicos de ablación y trasplante, proporcionándoles ayuda operativa adecuada, en cuya hipótesis serán reembolsados (Brasil, 2007).

\section{Ley $n .^{\circ} 15.463 / 2014$}

Instituye el mes de la donación de órganos, llamado "Septiembre Verde" en el estado de São Paulo. Representa un hito para el trasplante en Brasil, ya que incentiva la práctica de actividades de concientización y educación, sensibilizando a la comunidad sobre la donación y el trasplante de órganos (Brasil, 2014).

\section{Decreto n. ${ }^{\circ} 9.175 / 2017$}

Este Decreto deroga, desde el 18 de octubre de 2017, el Decreto n. ${ }^{\circ} 2.268 / 97$, y reglamenta la Ley n. ${ }^{\circ} 9.434 / 97$.

En el artículo $3^{\circ}$ son nominalmente incluidos, en el Sistema Nacional de Trasplantes (SNT), los Centros Estatales de Trasplantes (CET), el Centro Nacional de Trasplantes (CNT) y las estructuras especializadas en la búsqueda y donación y en el proceso para la preservación ex situ de órganos, tejidos, células y partes del cuerpo humano para el trasplante. Fue establecido, en el párrafo $1^{\circ}$ del artículo $5^{\circ}$, que solo podrán realizar trasplantes los estados que cuenten con Centro Estatal de Trasplantes (CET).

Se estipula que la extracción de órganos, tejidos, células y partes del cuerpo humano para trasplante o injerto puede llevarse a cabo cuando hay un diagnóstico de muerte encefálica y consentimiento expreso de la familia. El artículo 20 define que la autorización debe ser del cónyuge, pareja o pariente consanguíneos, mayor de edad y legalmente capaz, en línea directa o colateral hasta el segundo grado. Si la autorización es de pariente de segundo grado, deben ser explicadas las razones que impiden la autorización de familiares de primer grado. La extracción de órganos, tejidos, células y partes 
del cuerpo humano de un menor de edad fallecido requiere autorización expresa de ambos padres. Los demás casos, no comprendidos en las situaciones anteriores, requieren autorización judicial.

En cuanto a la donación de órganos, tejidos, células y partes del cuerpo en vida, se define que el receptor debe ser el cónyuge, compañero o pariente hasta el cuarto grado de consanguinidad en línea directa o colateral. Los casos no encuadrados en estas condiciones requieren autorización judicial, a excepción de la donación de médula ósea. Adicionalmente, el comité de bioética o comité de ética del hospital que llevará a cabo el trasplante o injerto debe emitir opinión en los casos de donación entre no consanguíneos que no sean cónyuges o pareja. Las mujeres embarazadas no pueden donar órganos, tejidos, células y partes del cuerpo, excepto médula ósea cuando no hubiera riesgo para su salud y la del feto. Por otra parte, una embarazada puede autorizar, antes del parto, la donación de células progenitoras de la sangre del cordón umbilical del recién nacido.

El capítulo VI del decreto trata sobre donantes y receptores extranjeros. Establece que los extranjeros que eventualmente fallezcan en Brasil pueden ser donantes y pueden también disponer de órganos, tejidos, células o partes del cuerpo en vida, aplicándoseles las mismas exigencias que a los donantes brasileños. Para llevar a cabo un trasplante o injerto en un paciente extranjero, este debe residir en Brasil, excepto en los casos de donación en vida a cónyuge, compañero o pariente consanguíneo hasta el cuarto grado, en línea directa o colateral. En caso de indicación aguda de trasplante, con riesgo de muerte inminente, el SNT podrá autorizar la inscripción en lista de espera de un extranjero no residente en Brasil.

El Ministerio de la Salud puede pedir la asistencia de la Fuerza Aérea Brasileña para el transporte de órganos, tejidos y partes del cuerpo humano. La FAB mantendrá permanentemente disponible al menos una aeronave para esta misión.

\section{Resolución n. ${ }^{\circ}$ 2.173/17 del Consejo Federal de Medicina}

De acuerdo con la revisión de la reglamentación de la Ley n..$^{\circ}$ 9.434/97, que dio lugar a la promulgación del Decreto n..$^{\circ}$ 9.175/17, y teniendo en cuenta la mejor comprensión de la fisiopatología de la muerte encefálica habida actualmente, el CFM publicó, el 15 de diciembre de 2017, la nueva resolución que define los criterios para el diagnóstico de la muerte encefálica (CFM, 2017).

Ya en el artículo $1^{\circ}$ de dicha resolución se observan nuevos prerrequisitos sobre la condición del paciente con posible muerte encefálica. Además de los criterios clínicos de coma arreactivo, arreactividad supraespinal y apnea, y lesión encefálica de causa conocida, irreversible y compatible con muerte encefálica, es necesario que el paciente esté bajo tratamiento y observación durante al menos 6 horas en un hospital. Es necesario, también, que los parámetros de temperatura corporal, saturación arterial de oxígeno y presión arterial sistólica o presión arterial media estén dentro de valores establecidos (CFM, 2017).

Para la determinación de la ME se exige la realización de al menos dos exámenes clínicos neurológicos, un examen auxiliar que compruebe la ausencia de actividad cerebral y una prueba de apnea. Estos deben ser registrados en la "Declaración de Muerte Encefálica" y en la historia clínica del paciente (CFM, 2017).

Con respecto a los exámenes clínicos necesarios para el diagnóstico de la muerte encefálica, especifica el artículo $3^{\circ}$ que estos son realizados por observación de coma arreactivo y de arreactividad supraespinal. Ratifica que cada examen debe ser realizado por un médico diferente, uno de los cuales debe ser especialista en neurología, neurocirugía, neurología pediátrica, medicina intensiva, medicina intensiva pediátrica o medicina de emergencia. En caso de que sea imposible que un especialista concluya el examen, este puede ser realizado por un médico específicamente capacitado, que es, según los criterios del CFM, aquel que tiene al menos un año de experiencia en el cuidado de pacientes en estado de coma y ha acompañado o realizado al menos diez diagnósticos de muerte encefálica, o que ha realizado curso de capacitación para el diagnóstico de muerte encefálica. Redefine, además, el intervalo entre los exámenes clínicos, que son descritos en el párrafo $4^{\circ}$ del artículo $3^{\circ}$ de la siguiente forma: de 7 días a 2 meses incompletos: 
24 horas; de 2 meses a 2 años incompletos: 12 horas; y a partir de 2 años: 1 hora. El artículo $6^{\circ}$ introduce una importante modificación a los procedimientos de exámenes clínicos para determinación de la muerte encefálica, ya que permite la continuidad de la investigación en pacientes que presenten alteraciones morfológicas, orgánicas, congénitas o adquiridas que impidan la evaluación bilateral de los reflejos fotomotor, corneopalpebral, vestíbulo-ocular y la respuesta a prueba calórica, cuando la razón de la imposibilidad esté fundamentada en la historia clínica (CFM, 2017).

La prueba de apnea, que antes formaba parte del examen clínico, ahora debe realizarse una sola vez. El laudo del examen auxiliar para comprobación de ausencia de perfusión sanguínea, de actividad metabólica o de actividad electroencefálica debe ser expedido por especialista en el método elegido en situaciones de muerte encefálica (CFM, 2017).

Debe brindarse información sobre el diagnóstico de ME a los familiares o responsables legales del paciente, así como sobre los resultados de cada etapa del procedimiento. Esta comunicación debe ser realizada por el médico a cargo del paciente o su sustituto, y debe ser registrada en la historia clínica. Como se describe en el formulario de "Declaración de Muerte Encefálica”, debe obligatoriamente comunicarse al Comité Intrahospitalario de Donación de Órganos y Tejidos para Trasplante (сіндотт), Organización de Obtención de Órganos (OPO) o Centro Estatal de Trasplantes (CET) cuando se inicia el procedimiento para la determinación de muerte encefálica, cuando el primer examen clínico y la prueba de apnea resultan compatibles con muerte encefálica y cuando se diagnostica de muerte encefálica mediante el segundo examen clínico y examen auxiliar compatibles (CFM, 2017).

La resolución también corrobora la decisión de la Resolución CFM n. ${ }^{\circ} 1.826 / 07$, que otorga al médico la autoridad ética y legal para suspender los procedimientos y el soporte terapéutico en uso cuando es constatada la muerte encefálica, excepto si se trata de un donante de órganos, tejidos o partes del cuerpo humano para trasplante (CFM, 2017). La tabla 2 ilustra los marcos legales del proceso de donación y trasplante en Brasil.

\section{Consideraciones finales}

El proceso de donación y trasplante de órganos es objeto de debates y controversias que se reflejan en los cambios en la legislación que se describen en este artículo. En este contexto, es necesario tomar decisiones basadas en la ética profesional, en preceptos morales y en la legislación vigente, así como respetando los aspectos religiosos y sociales de los individuos involucrados.

En 1998, durante la vigencia de la obligatoriedad de la elección según la cual el individuo expresaba su voluntad de ser o no donante en el documento de identidad, la Asociación Brasileña de Trasplante de Órganos (ABTO) realizó una encuesta en los organismos de identificación y de tránsito sobre la opción negativa sobre donación en los documentos emitidos. El triste resultado de ese relevamiento mostró que en el estado de Sergipe, el 94\% de los documentos expedidos por los organismos de identificación incluían el término "no donante", y que en Bahía ese porcentaje era de $90 \%$. Los mejores resultados fueron en Río Grande del Sur, donde 19\% de los documentos expedidos por los organismos de identificación y el $49 \%$ de los emitidos por los organismos de tránsito eran negativos sobre donación. Se estimaba que más de la mitad de la población brasileña estaba catalogada como no donante, lo que impedía que la donación de órganos y tejidos fuera siquiera propuesta a esas familias.

Los datos del Registro de Trasplantes de Brasil, organizado por la A BTO también en 1998, corroboraron la realidad de la deficiente cobertura de las necesidades de trasplante en todo el país. En el estado de Bahía, el 96\% de los donantes identificados como potenciales resultaron en negativa a la donación, ya sea debido al documento de identidad o a la decisión de la familia; en Río Grande del Sur, este porcentaje fue del $58 \%$.

Los cambios en la legislación de donación y trasplante en Brasil fueron consecuencia de la respuesta de la población a la donación. La opción por el consentimiento familiar a la donación de órganos permitió que el tema fuera tratado de manera más amena y reflexiva, lo que resultó en mejores índices de donación. Entre enero y septiembre de 2017, de acuerdo con el Registro de Trasplantes 
Tabla 2. Marcos legales del proceso de donación y trasplante

\begin{tabular}{|c|c|c|}
\hline Legislación & Contenido & $\begin{array}{l}\text { Carácter de } \\
\text { la donación }\end{array}$ \\
\hline $\begin{array}{l}\text { Ley }^{\circ} .^{\circ} \\
9.434 / 97\end{array}$ & $\begin{array}{l}\text { Se ocupa de la disposición post mortem de tejidos, órganos y partes del cuerpo humano para trasplante, } \\
\text { de los criterios para el trasplante con donante vivo y las sanciones penales y administrativas en caso de } \\
\text { incumplimiento. Se considera que el individuo es donante de órganos, salvo manifestación de voluntad en } \\
\text { contrario expresada mediante la inclusión del término "no donante" en documento de identidad. }\end{array}$ & \multirow{3}{*}{$\begin{array}{l}\text { Donación } \\
\text { supuesta }\end{array}$} \\
\hline $\begin{array}{l}\text { Decreto } .^{\circ} \\
2.268 / 97\end{array}$ & $\begin{array}{l}\text { Reglamenta la Ley } 9.434 / 97 \text {, siendo su principal contribución acerca del carácter de la donación. Aun } \\
\text { habiendo optado por ser donante o no donante, el individuo podía comparecer en cualquier momento } \\
\text { a los organismos oficiales de identificación civil y de tránsito que registraron su opción, y renovar los } \\
\text { documentos. }\end{array}$ & \\
\hline $\begin{array}{l}\text { Res. CFM n. } \\
1.480 / 97\end{array}$ & $\begin{array}{l}\text { Considerando el artículo } 3^{\circ} \text { de la Ley 9.434/97, que atribuye al Consejo Federal de Medicina la selección } \\
\text { de los criterios para la determinación de la muerte encefálica, el cFm promulgó esta resolución. }\end{array}$ & \\
\hline $\begin{array}{l}\text { Ley }^{\circ} .^{\circ} \\
10.211 / 01\end{array}$ & $\begin{array}{l}\text { Con la promulgación de la Ley } 10.211 \text {, todas las formas de registro en documentos oficiales pierden } \\
\text { valor; la donación deja de ser supuesta y pasa a ser denominada consentida. }\end{array}$ & \multirow{4}{*}{$\begin{array}{l}\text { Donación } \\
\text { Consentida }\end{array}$} \\
\hline $\begin{array}{l}\text { Ley n. }^{\circ} \\
15.463 / 14\end{array}$ & $\begin{array}{l}\text { Instituye el mes de la donación de órganos, llamado "Septiembre Verde" en el estado de São Paulo. } \\
\text { Representa un hito para el trasplante en Brasil, ya que incentiva la práctica de actividades de } \\
\text { concientización y educación en la comunidad. }\end{array}$ & \\
\hline $\begin{array}{l}\text { Decreto } .^{\circ} \\
9.175 / 17\end{array}$ & $\begin{array}{l}\text { Deroga el Decreto n. }{ }^{\circ} 2.268 / 97 \text { y reglamenta la Ley n. }{ }^{\circ} 9.434 / 97 \text {. Estipula que la autorización para la } \\
\text { donación debe ser del cónyuge, pareja o pariente consanguíneos, mayor de edad y legalmente capaz, } \\
\text { en línea directa o colateral hasta el segundo grado. Si la autorización es de pariente de segundo grado, } \\
\text { deben ser explicadas las razones que impiden la autorización de familiares de primer grado. Sobre la } \\
\text { donación en vida, se define que el receptor debe ser cónyuge, compañero o pariente hasta el cuarto } \\
\text { grado de consanguinidad en línea directa o colateral. Otros casos requieren autorización judicial, a } \\
\text { excepción de la donación de médula ósea. }\end{array}$ & \\
\hline $\begin{array}{l}\text { Res. CFM n. } \\
2.173 / 17\end{array}$ & $\begin{array}{l}\text { Teniendo en cuenta la mejor comprensión actual de la fisiopatología de la muerte encefálica, el cFM } \\
\text { publicó, el } 15 \text { de diciembre de 2017, la nueva resolución definiendo criterios para diagnóstico de la } \\
\text { muerte encefálica. }\end{array}$ & \\
\hline
\end{tabular}

Fuente: autoría propia.

de Brasil, de la Авто, el promedio de negativa familiar a la donación, a nivel nacional, fue de $42 \%$. El mejor resultado fue registrado en el estado de Paraná, donde las negativas no superaron el $31 \%$, y en el estado de Bahía, que sufría de déficit de donaciones cuando el régimen de consentimiento era otro, las negativas fueron del $60 \%$.

Está claro que los mejores resultados en donación de órganos en Brasil dependen de tres factores: que la población esté dispuesta a donar, que los familiares conozcan el deseo de ser donante de la persona fallecida y que las familias de los potenciales donantes sean correctamente abordadas. Una legislación comprensible, confiable y amplia sobre el tema fortalece estos tres pilares, dando a los individuos seguridad en su decisión de ser donantes, garantizando a las familias el respeto al deseo de su ser querido e instruyendo y capacitando a los profesionales para llevar a cabo la entrevista con la familia de la manera más benéfica posible.

Desde esta perspectiva, es esencial que los profesionales de la salud posean, además de conocimientos técnicos, conocimientos jurídicos y comprensión de las normas existentes y su evolución, con el fin de garantizar los derechos fundamentales de las personas.

\section{Referencias}

AвTо (2019). Registro Brasileiro de Transplantes: Janeiro-Setembro de 2018. Disponível em: https://goo.gl/13VfGK

Acero, MT. (2011). ¿Por qué en Colombia no está generalizada la práctica de la donación de órganos? Una mirada desde la Bioética. Revista Latinoamericana de Bioética, 11(20), 56-67.

Brasil (1968). Ley n. ${ }^{\circ}$ 5.479, de 10 de agosto de 1968. Dispõe sobre a retirada e transplante de tecidos, órgãos e partes de 
cadáver para finalidade terapêutica e científica, e dá outras providências. Disponível em: https://goo.gl/UZXJqJ

Brasil (1988). Constituição da República Federativa do Brasil: texto constitucional promulgado em 5 de outubro de 1988, com as alterações determinadas pelas Emendas Constitucionais de Revisão nos 1 a 6/94, pelas Emendas Constitucionais n. $1 / 92$ a 91/2016 e pelo Decreto Legislativo n. ${ }^{\circ}$ 186/2008. - Brasília: Senado Federal, Coordenação de Edições Técnicas, 2016. Disponível em: https:// goo.gl/N3EPZd

Brasil (1992). Ley n. 8.489 de 18 de novembro de 1992. Dispõe sobre a retirada e transplante de tecidos, órgãos e partes do corpo humano, com fins terapêuticos e científicos e dá outras providências. Disponível em: https:// goo.gl/FtrmUf

Brasil (1993). Decreto n. ${ }^{\circ} 879$, de 22 de julho de 1993. Regulamenta a Lei $\mathrm{n}^{\circ} 8.489$, de 18 de novembro de 1992, que dispõe sobre a retirada e o transplante de tecidos, órgãos e partes do corpo humano, com fins terapêuticos, científicos e humanitários. Disponível em: https:// goo.gl/BDREyu

Brasil (1997). Decreto n. ${ }^{\circ}$ 2.170, de 4 de Março de 1997. Dá nova redação ao art. $2^{\circ}$ do Decreto n. ${ }^{\circ} 89.250$, de 27 de dezembro de 1983, que regulamenta a Lei n. ${ }^{\circ} 7.116$, de 29 de agosto de 1983, que assegura validade nacional às Carteiras de Identidade, regula sua expedição, e dá outras providências. Disponível em: https://goo.gl/NjxcqL

Brasil (1997). Decreto n. ${ }^{\circ} 2.268$, de 30 de junho de 1997. Regulamenta a Lei n. ${ }^{\circ}$ 9.434, de 4 de fevereiro de 1997, que dispõe sobre a remoção de órgãos, tecidos e partes do corpo humano para fim de transplante e tratamento, e dá outras providências. Disponível em: https://goo.gl/ g7cbpn

Brasil (1997). Lei n. ${ }^{\circ}$ 9.434, de 4 de fevereiro de 1997. Dispõe sobre a remoção de órgãos, tecidos e partes do corpo humano para fins de transplante e tratamento e dá outras providências. Disponível em: https://goo. gl/1gRGWF

Brasil (2000). Medida Provisória n. ${ }^{\circ}$ 1959, de 21 de dezembro de 2000. Altera dispositivos da Lei no 9.434, de 4 de fevereiro de 1997, que dispõe sobre a remoção de órgãos, tecidos e partes do corpo humano para fins de transplante e tratamento. Disponível em: https:// goo.gl/F49mQ8

Brasil (2001). Lei n. ${ }^{\circ}$ 10.211, de 23 de março de 2001. Altera dispositivos da Lei n. ${ }^{\circ}$ 9.434, de 4 de fevereiro de 1997, que “dispõe sobre a remoção de órgãos, tecidos e partes do corpo humano para fins de transplante e tratamento”. Disponível em: https://goo.gl/o7ciX8

Brasil (2007). Lei n. ${ }^{\circ} 11.521$, de 18 de setembro de 2007. Altera a Lei $n .^{\circ} 9.434$, de 4 de fevereiro de 1997, para permitir a retirada pelo Sistema Único de Saúde de órgãos e tecidos de doadores que se encontrem em instituições hospitalares não autorizadas a realizar transplantes. Disponível em: https://goo.gl/agPhvr

Brasil (2014). Lei n. ${ }^{\circ} 15.463$, de 18 de junho de 2014. Institui o mês da doação de órgãos, denominado "Setembro Verde”. Disponível em: https://goo.gl/qr92k8

Brasil (2017). Decreto n. ${ }^{\circ}$ 9.175, de 18 de outubro de 2017. Regulamenta a Lei n. ${ }^{\circ} 9.434$, de 4 de fevereiro de 1997, para tratar da disposição de órgãos, tecidos, células e partes do corpo humano para fins de transplante e tratamento. Disponível em: https:/goo.gl/SxYnvA

Chaparro, GR. (2017). La presunción de la donación de órganos en Colombia: reflexiones para el debate. Revista Latinoamericana de Bioética, 17(33-2), 92-106.

Conselho Federal de Medicina (2017). Resolução CFM n. ${ }^{\circ}$ 2.173/17. Brasília: CFM, 2017. Disponible en: https:// goo.gl/KCuo5g

Conselho Federal de Medicina. Resolução (1997). CFM n. ${ }^{\circ}$ 1.480/97. Brasília: CFM, 1997. Disponible en: https:/goo. gl/7Ehe9y

Dantas, E. (2012). Direito médico. Rio de Janeiro: GZ Editora.

De Ortuzar, MG., Soratti, C. \& Vélez, I. (1997, December). Bioethics and organ transplantation. In Transplantation proceedings, 29(8), 3627-3630. Elsevier.

Freitas, GF (2007). "Conceituação sobre direito e normas éticas e legais”. In: T. Oguisso, (Org.), Trajetória histórica e legal da enfermagem. 2a edição, São Paulo, Brasil: Monole.

Hospital Israelita Albert Einstein (2019). Sociedade Beneficente Israelita Brasileira. Transplante de Órgãos. Disponível em: https://goo.gl/GppyvG

IBGE (2017). Pesquisa Nacional por Amostra de Domicílios Contínua - PNAD Contínua. Disponível em: https:// goo.gl/pWV9cv

Kennedy, I., Sells, RA., Daar, AS., Guttmann, RD., Hoffenberg, R., Lock, M. \& Tilney, N. (1998). The case for "presumed consent" in organ donation. The Lancet, 351(9116), 1650-1652.

Medeiros, M. (1999). Princípios de justiça na alocação de recursos em saúde. Disponível em: https://goo.gl/w1YLZ5

Ribeiro, DC. (2006). Autonomy: to live one's own life and to die one's own death. Cadernos de Saúde Pública, 22(8), 1749-1754.

Roza, BA, Garcia, VD, Barbosa, SFF, Mendes, KDS e Schirmer, J. (2010). Doação de órgãos e tecidos: relação com o corpo em nossa sociedade. Acta Paulista de Enfermagem, 23(3), 417-422. 
Sharif, A. (2018). Presumed consent will not automatically lead to increased organ donation. Kidney international, 94(2), 249-251.

Ventura, CAA, Mello, DF, Andrade, RD e Mendes, IAC. (2012). Aliança da enfermagem com o usuário na defesa do sus. Rev Bras Enferm, Brasília, 65(6), 893-898.
World Health Organization (2010). wHO guiding principles on human cells, tissue and transplantation. Disponível em: https://goo.gl/p5Wqt9

World Health Organization (2016). Transplantation of human cells, tissues and organs. Disponível em: https:/goo.gl/8D4MWQ 